\title{
A Descriptive Study of Nosocomial Infections in an Adult Intensive Care Unit in Fiji: 2011-12
}

\author{
Keshni Naidu, ${ }^{1}$ Ilisapeci Nabose, ${ }^{2}$ Sharan Ram, ${ }^{1}$ Kerri Viney, ${ }^{3,4}$ \\ Stephen M. Graham, ${ }^{5,6}$ and Karen Bissell ${ }^{5,7}$ \\ ${ }^{1}$ College of Medicine, Nursing \& Health Sciences, Fiji National University, Suva, Fiji \\ ${ }^{2}$ Colonial War Memorial Hospital, Ministry of Health, Suva, Fiji \\ ${ }^{3}$ Public Health Division, Secretariat of the Pacific Community, Noumea, New Caledonia \\ ${ }^{4}$ National Centre for Epidemiology and Population Health, Research School of Population Health, \\ Australian National University, Canberra, Australia \\ ${ }^{5}$ International Union Against Tuberculosis and Lung Disease, Paris, France \\ ${ }^{6}$ Centre for International Child Health, Department of Paediatrics, \\ University of Melbourne and Murdoch Children Research Institute, Royal Children's Hospital, Melbourne, VIC, Australia \\ ${ }^{7}$ The University of Auckland, Auckland, New Zealand
}

Correspondence should be addressed to Keshni Naidu; keshni78@gmail.com

Received 26 June 2014; Accepted 25 August 2014; Published 17 September 2014

Academic Editor: Peter Leggat

Copyright (C) 2014 Keshni Naidu et al. This is an open access article distributed under the Creative Commons Attribution License, which permits unrestricted use, distribution, and reproduction in any medium, provided the original work is properly cited.

\begin{abstract}
Nosocomial infections in an intensive care unit (ICU) are common and associated with a high mortality but there are no published data from the Oceania region. A retrospective study in Fijis largest ICU (2011-12) reported that 114 of a total 663 adult ICU admissions had bacteriological culture-confirmed nosocomial infection. The commonest sites of infection were respiratory and bloodstream. Gram negative bacteria were the commonest pathogens isolated, especially Klebsiella pneumoniae (extendedspectrum $\beta$-Lactamase-producing), Acinetobacter, and Pseudomonas species. Mortality for those with a known outcome was $33 \%$. Improved surveillance and implementation of effective preventive interventions are needed.
\end{abstract}

\section{Introduction}

Health-care-associated (or nosocomial) infection is a major problem in hospitals worldwide and the prevalence is two- to threefold higher in developing countries compared to Europe or USA $[1,2]$. The incidence is particularly high in intensive care units (ICUs) compared to non-ICU wards in the hospital as ICU patients have a range of severe comorbidities and the use of invasive devices during their management is very common [3]. Reports from a range of ICU settings including those in developing countries consistently show a high burden of device-associated nosocomial infections [4-6]. Nosocomial infections are caused by a wide range of pathogens, and ventilator-associated pneumonia and central line infections are common sites of infections and are associated with high mortality-as high as $50 \%$. Nosocomial infections are associated with an increase in crude mortality, length of stay in ICU, and hospital costs [7-10].

There are no published data reporting the prevalence of nosocomial infections in Fiji. Such information is required to describe the current epidemiology and to improve infection control practices in the adult ICU. This retrospective study aimed to describe bacteriological culture-confirmed nosocomial infections in Fijis largest adult ICU.

\section{Materials and Methods}

2.1. Study Design and Setting. This was a retrospective, descriptive study of bacteriological culture-confirmed nosocomial infections in an adult ICU in 2011 and 2012. The study was conducted at the Colonial War Memorial Hospital 
$(\mathrm{CWMH})$ in Suva, Fiji. The adult ICU ward at the CWMH has 6 beds and is the largest ICU ward in Fiji. There is a separate ICU ward for children and neonates (0-14 years). The adult ICU provides care for both ventilated and nonventilated patients and a mix of medical and general surgical patients. Patients may be admitted directly from the community or from other hospital wards.

2.2. Study Population. The study only included patients with clinical features of invasive sepsis who had a bacterial pathogen isolated on culture from at least one specimen taken from the patient more than 48 hours after admission to the ICU, that is, those with clinically suspected nosocomial sepsis that was microbiologically confirmed. When the onset of invasive sepsis is clinically suspected on the basis of the patient developing evidence of a systemic inflammatory response syndrome (SIRS, see Box 1), samples from venous blood, body sites, and devices are sent for bacterial culture. The attending clinician selects the samples to be sent as clinically indicated on the basis of the likely site of infection. Patients admitted to the ICU with sepsis were not included unless they developed new signs of SIRS (Box 1) more than 48 hours after admission. Patients with suspected sepsis without microbiological confirmation were also not included.

Blood cultures were processed using the BACT/ALERT 3D system (BioMerieux, Marcy L'Etoile, France) and incubated at $36^{\circ} \mathrm{C}$ for 7 days. If a blood culture bottle was flagged positive, a Gram stain was performed on one drop of the culture fluid. Subculture was performed using selective and nonselective agar depending on the Gram stain result. Gram negative organisms were identified using the Microbact Identification Kit (Oxoid, Basingstoke, UK).

Data were sourced from the infection control surveillance records and the ICU patient records with cross-checking between these records and the microbiology laboratory records. Data collected for all ICU admissions for 2011-2012 included numbers of admissions, devices used, and number of days the devices were used. The patient name was used for cross-checking between registers but not included in data entry or data storage.

Data were collected in a structured proforma using a unique identification number and the following variables were entered: age, date of admission, date of specimen collection, length of stay in ICU, and bacterial pathogens isolated and from which specimen the pathogen was isolated. Respiratory specimens include those that were taken from the respiratory tract-usually aspiration of endotracheal or tracheostomy tubes from ventilated patients-or pleural aspirates while blood stream infections include those taken from peripheral blood cultures, those samples taken through a venous cannula device such as a central venous line and catheter tips.

Data were double entered into EpiData version 3.1 (EpiData Association, Odense, Denmark). The rate of nosocomial infections was calculated by dividing the number of patients with nosocomial infections by the total number of patients in
TABLE 1: Characteristics of bacteriologically-confirmed nosocomial infections from an adult intensive care unit 2011-2012.

\begin{tabular}{lccc}
\hline & 2011 & 2012 & Total \\
& $N=58$ & $N=56$ & $N=114$ \\
\hline Age & $15(26)$ & $14(25)$ & 29 \\
15-30 yrs & $30(52)$ & $29(52)$ & 59 \\
31-60 yrs & $12(21)$ & $12(21)$ & 24 \\
61-100 yrs & - & $2(4)$ & 2 \\
Unknown & & & \\
Sex & $38(66)$ & $34(60)$ & 72 \\
Male & $19(33)$ & $21(38)$ & 40 \\
Female & & $2(4)$ & 2 \\
Unknown & & & \\
Admission status & $15(26)$ & $19(34)$ & 34 \\
Direct admission & $43(74)$ & $36(64)$ & 79 \\
Transferred & & $1(2)$ & 1 \\
Unknown & & & \\
Length of stay & $18(31)$ & $8(14)$ & 26 \\
1-7 days & $20(34)$ & $22(39)$ & 42 \\
8-14 days & $10(17)$ & $7(13)$ & 17 \\
15-21 days & $7(12)$ & $11(20)$ & 18 \\
22-31 days & $2(3)$ & $7(13)$ & 9 \\
31 days and more & $1(2)$ & $1(2)$ & 2 \\
Unknown & & & \\
Mechanical Ventilation & $57(98)$ & $54(96)$ & 111 \\
Ventilated & 0 & $1(2)$ & 1 \\
Not ventilated & & & \\
Unknown & & & \\
Patient outcomes & & & \\
Transferred from ICU & $35(60)$ & 38 \\
Deceased & & & \\
Unknown & & & \\
\hline
\end{tabular}

the ICU during the same study period. Numbers of isolates per site of specimen are presented.

\section{Results}

There were 663 patients admitted to the ICU during the twoyear study period. This represented 2891 total patient days of admission during which patients were ventilated for 2175 days. Of the 663 admissions, 114 (17\%) developed cultureconfirmed nosocomial sepsis. Table 1 lists the characteristics of the study patients. The majority of the patients had prior admission to other wards before admission to ICU. Males were more commonly represented than females and almost all patients had been mechanically ventilated with a median period of 8 days of ventilation.

Table 2 lists the bacterial pathogens isolated and the sites from which they were isolated. The largest proportion was from respiratory tract specimens. There were 437 isolates 
Temperature (onset of fever) $>38^{\circ} \mathrm{C}$

Increased white cell count $>12,000^{3}$

Increased heart rate $>90$ beats per minute

Tachypnoea $>20$

New chest infiltrates

Purulent endotracheal/tracheal discharges

Box 1: Indicators of a systemic inflammatory response.

TABLE 2: Distribution of bacterial pathogens associated with nosocomial infection in relation to site of specimen.

\begin{tabular}{|c|c|c|c|c|c|}
\hline \multirow{2}{*}{ Pathogen } & \multicolumn{4}{|c|}{ Site of pathogen } & \multirow{2}{*}{$\begin{array}{l}\text { Total } \\
N=437\end{array}$} \\
\hline & $\begin{array}{l}\text { Respiratory tract } \\
\qquad N=125\end{array}$ & $\begin{array}{c}\text { Blood } \\
N=122\end{array}$ & $\begin{array}{l}\text { Surgical site } \\
\quad N=102\end{array}$ & $\begin{array}{l}\text { Urinary tract } \\
\qquad N=88\end{array}$ & \\
\hline $\begin{array}{l}\text { Klebsiella pneumoniae } \\
\text { (ESBL producing }{ }^{\#} \text { ) }\end{array}$ & $34(27 \%)$ & $21(17 \%)$ & $18(18 \%)$ & $21(24 \%)$ & $94(22 \%)$ \\
\hline Acinetobacter species & $33(26 \%)$ & $21(17 \%)$ & $18(18 \%)$ & $20(23 \%)$ & $92(21 \%)$ \\
\hline Pseudomonas aeruginosa & $24(19 \%)$ & $11(9 \%)$ & $25(25 \%)$ & $13(15 \%)$ & $73(17 \%)$ \\
\hline Enterobacter species & $8(6.4 \%)$ & $9(7 \%)$ & $11(11 \%)$ & $5(6 \%)$ & $33(8 \%)$ \\
\hline $\begin{array}{l}\text { Coagulase-negative } \\
\text { Staphylococci }\end{array}$ & $1(0.8 \%)$ & $20(16 \%)$ & $1(0.9 \%)$ & $8(9 \%)$ & $30(7 \%)$ \\
\hline Escherichia coli & $2(1.6 \%)$ & $13(11 \%)$ & $2(2 \%)$ & $5(6 \%)$ & $22(5 \%)$ \\
\hline Other Klebsiella & $6(4.8 \%)$ & $2(1.6 \%)$ & $6(6 \%)$ & $5(6 \%)$ & $19(4 \%)$ \\
\hline $\begin{array}{l}\text { Other Gram negative } \\
\text { species }\end{array}$ & $5(4 \%)$ & $6(5 \%)$ & $6(6 \%)$ & 0 & $17(4 \%)$ \\
\hline Citrobacter species & $2(1.6 \%)$ & $2(1.6 \%)$ & $2(2 \%)$ & $3(3 \%)$ & $9(2 \%)$ \\
\hline $\mathrm{MRSA}^{\#}$ & $1(0.8 \%)$ & $1(0.8 \%)$ & $1(0.9 \%)$ & - & $3(0.2 \%)$ \\
\hline Others & $9(7.2 \%)$ & $16(13 \%)$ & $12(12 \%)$ & $8(9 \%)$ & $45(1.1 \%)$ \\
\hline
\end{tabular}

\#ESBL: extended spectrum $\beta$-lactamase; MRSA: methicillin resistant Staphylococcus aureus.

from 114 patients and so most patients had isolates cultured from multiple sites. Of patients, $66 \%$ had isolates from a respiratory specimen (endotracheal tube or pleural fluid), $49 \%$ from a urinary specimen (indwelling catheter or clean catch), $67 \%$ from a blood specimen (peripheral or central line), and $41 \%$ from a surgical site (wound swab or surgical drain). Gram negative bacteria such as Klebsiella pneumoniae, Acinetobacter species, and Pseudomonas aeruginosa were the commonest isolates. $K$. pneumoniae (extended-spectrum $\beta$-Lactamase (ESBL) producing) was isolated from blood and urine in $21 \%$ of patients simultaneously. Coagulasenegative staphylococci were most commonly isolate from blood. Pseudomonas aeruginosa was the commonest isolate from surgical site specimens.

Outcome was known in 84\% (96/114) patients and $40 \%$ (38/96) with known outcome died in ICU (Table 1). Of 63 patients with a bacterial isolate from the blood and a known outcome, $21(33 \%)$ died, compared to 50\% (16/32) among those with a known outcome but without a bacterial isolate from the blood. Of those that died, 55\% (21/38) had a blood stream infection.

\section{Discussion}

This study provides original descriptive data from Fiji of common nosocomial bacterial infections in ICU. A recent global systematic review of the published literature on the burden of nosocomial infections in developing countries did not identify previously published data from the Pacific Island region [1]. The commonest sites of infection were respiratory tract and bloodstream infections, and Gram negative bacteria were the main pathogens isolated from ICU patients. These findings are consistent with other studies from developing countries [1, 4-11].

Mortality was very high among these ICU patients with nosocomial infections. High mortality has been previously reported from developing countries ICUs $[6,10]$. It is difficult to ascertain the additional attributable risk of nosocomial infection to mortality in these patients and settings as overall mortality is high in ICU patients and length of stay of ICU patients is linked with the comorbidities that the patients have prior to admission to ICU. The average length of stay for our patients was 4 days but with a wide range of 
up to over 30 days - such as for patients with trauma or Guillain-Barre syndrome. Patients in the ICU were ventilated for the majority of the time spent in ICU, on average for $75 \%$ of their stay. However, we were unable to determine relationships between nosocomial infection and outcomes such as mortality and length of stay in our retrospective study. A previous study estimated that ventilator-associated pneumonia, which is one of the commonest ICU-related nosocomial infections, was associated with a $14 \%$ increase in risk of mortality and a prolonging of the ICU stay by two days [10].

In this study, Gram negative bacteria were the predominant pathogens isolated with Klebsiella, Acinetobacter, and Pseudomonas the commonest isolate. These pathogens are commonly isolated from patients in ICUs and the prevalence of pathogens can change over time [3-6, 12-14]. There was a recent outbreak of Acinetobacter in the ICU of CWMH during the study period (August-December 2012). Gram positives were less prevalent with the commonest being coagulase-negative staphylococci and it is difficult to know whether this is a pathogen or skin contaminant [13]. It was most commonly isolated from blood specimens that are often taken through intravenous lines. Notably, methicillinresistant Staphylococcus aureus was not commonly isolated. Nosocomial pathogens are frequently resistant to multiple antibiotics. We do not present antibiotic susceptibility data except to note that ESBL-producing Klebsiella was very common. K. pneumoniae is well recognized to have emerged as important ESBL-producing bacteria, and the other common bacteria found in this study such as Acinetobacter and Pseudomonas can also be ESBL-producing [13].

This study has a number of important limitations. It is a retrospective study that relies on previous data records for which accuracy and completeness cannot be validated. However, protocols and recording are structured and have been used for infection control purposes in the CWMH for many years. Data on the use of all devices over the study period were not available and so rates of nosocomial infection associated with specific device utilization over time could not be calculated. The data on outcome were also incomplete.

\section{Conclusion}

Despite these limitations, this study provides important baseline data that strongly suggest that infection control practices could be improved. There are known interventions that can reduce the burden of nosocomial infections in ICUs even in the resource-limited setting [15-19]. There needs to be improved recording and ongoing surveillance in order to monitor the burden of infections and evaluate interventions that can prevent nosocomial infections and reduce the risk of outbreaks.

\section{Ethical Approval}

Ethical approval was obtained from the Ethics Advisory Group of the International Union Against Tuberculosis and Lung Disease (The Union), the National Health Research
Ethics Committee, and the Fiji National Ethics Review Committee.

\section{Conflict of Interests}

The authors declare that there is no conflict of interests regarding the publication of this paper.

\section{Acknowledgments}

This research was conducted through the Structured Operational Research and Training Initiative (SORT IT). The training was run in Fiji by the College of Medicine, Nursing and Health Sciences, Fiji National University, Fiji and The Union. Additional support for running the course was provided by the Public Health Division of the Secretariat of the Pacific Community, New Caledonia; Centre for International Child Health, the University of Melbourne, Australia; School of Population Health, University of Queensland, Australia; Regional Public Health, Hutt Valley District Health Board, New Zealand; the National TB Programme, Fiji Ministry of Health, Fiji. Funding for the course was provided by the Global Fund to fight AIDS, TB, and malaria, with cofunding by The Union; the Special Programme for Research and Training in Tropical Diseases (TDR); Public Health Division of the Secretariat of the Pacific Community, New Caledonia; Centre for International Child Health, the University of Melbourne, Australia; School of Population Health, University of Queensland, Australia.

\section{References}

[1] B. Allegranzi, S. Bagheri Nejad, C. Combescure et al., "Burden of endemic health-care-associated infection in developing countries: systematic review and meta-analysis," The Lancet, vol. 377, pp. 228-241, 2011.

[2] S. B. Nejad, B. Allegranzi, S. B. Syed, B. Ellis, and D. Pittet, "Health-care-associated infection in Africa: a systematic review," Bulletin of the World Health Organization, vol. 89, pp. 757-765, 2011.

[3] J. S. Doyle, K. L. Buising, K. A. Thursky, L. J. Worth, and M. J. Richards, "Epidemiology of infections acquired in intensive care units," Seminars in Respiratory and Critical Care Medicine, vol. 32, pp. 115-138, 2011.

[4] A. R. Marra, L. F. A. Camargo, A. C. C. Pignatari et al., "Nosocomial bloodstream infections in Brazilian hospitals: analysis of 2.563 cases from a prospective nationwide surveillance study," Journal of Clinical Microbiology, vol. 49, no. 5, pp. 1866-1871, 2011.

[5] J. G. Ding, Q. F. Sun, K. C. Li et al., "Retrospective analysis of nosocomial infections in the intensive care unit of a tertiary hospital in China during 2003 and 2007," BMC Infectious Diseases, vol. 9, article 115, 2009.

[6] V. D. Rosenthal, D. G. Maki, R. Salomao et al., "Deviceassociated nosocomial infections in 55 intensive care units of 8 developing countries," Annals of Internal Medicine, vol. 145, pp. 582-591, 2006.

[7] D. Pittet, D. Tarara, and R. P. Wenzel, "Nosocomial bloodstream infection in critically ill patients. Excess length of stay, extra 
costs and attributable mortality," Journal of American Medical Association, vol. 271, pp. 1598-1601, 1994.

[8] V. D. Rosenthal, P. Lynch, W. R. Jarvis et al., "Socioeconomic impact on device-associated infections in limited-resource neonatal intensive care units: findings of the INICC,' Infection, vol. 39, no. 5, pp. 439-450, 2011.

[9] P. Ylipalosaari, T. I. Ala-Kokko, J. Laurila, P. Ohtonen, and H. Syrjala, "Intensive care acquired infection is an independent risk factor for hospital mortality: a prospective cohort study," Critical Care, vol. 10, article R66, 2006.

[10] V. D. Rosenthal, F. E. Udwadia, H. J. Muñoz et al., “ International Nosocomial Infection Control Consortium (2011) Timedependent analysis of extra length of stay and mortality due to ventilator-associated pneumonia in intensive-care units of ten limited-resources countries: findings of the International Nosocomial Infection Control Consortium (INICC)," Epidemiology \& Infection, vol. 139, no. 11, pp. 1757-1763, 2011.

[11] J. A. Navoa-Ng, R. Berba, Y. A. Galapia et al., "Device-associated infections rates in adult, pediatric, and neonatal intensive care units of hospitals in the Philippines: international Nosocomial Infection Control Consortium (INICC) findings," American Journal of Infection Control, vol. 39, no. 7, pp. 548-554, 2011.

[12] R. P. Fagan, B. J. Edwards Park Jr., S. K. Fridkin, and S. S. Magil, "Incidence trends in pathogen-specific central line-associated bloodstream infections in US Intensive Care Units," Infection Control and Hospital Epidemiology, vol. 34, pp. 893-899, 2013.

[13] G. A. Jacoby and L. S. Munoz-Price, "The new $\beta$-lactamases," The New England Journal of Medicine, vol. 352, no. 4, pp. 380391, 2005.

[14] S. Khanal, D. R. Joshi, D. R. Bhatta, U. Devkota, and M. N. Pokhrel, “ $\beta$-lactamase-producing multidrug-resistant bacterial pathogens from tracheal aspirates of intensive care unit patients at National Institute of Neurological and Allied Sciences, Nepal," ISRN Microbiology, vol. 2013, Article ID 847569, 5 pages, 2013.

[15] O. Rewa, J. Muscedere, S. Reynolds, and X. Jiang, "Coagulasenegative Staphylococcus, catheter-related, bloodstream infections and their association with acute phase markers of inflammation in the intensive care unit: an observational study," The Canadian Journal of Infectious Diseases \& Medical Microbiology, vol. 23, no. 4, pp. 204-208, 2012.

[16] V. D. Rosenthal, S. Guzman, and C. Crnich, "Impact of an infection control program on rates of ventilator-associated pneumonia in intensive care units in 2 Argentinean hospitals," American Journal of Infection Control, vol. 34, no. 2, pp. 58-63, 2006.

[17] F. Franzetti, B. Borghi, F. Raimondi, and V. D. Rosenthal, "Impact on rates and time to first central vascular-associated bloodstream infection when switching from open to closed intravenous infusion containers in a hospital setting," Epidemiology \& Infection, vol. 137, pp. 1041-1048, 2009.

[18] V. D. Rosenthal, D. G. Maki, C. Rodrigues et al., "International Nosocomial Infection Control Consortium Investigators (2010) Impact of International Nosocomial Infection Control Consortium (INICC) strategy on central line-associated bloodstream infection rates in the intensive care units of 15 developing countries," Infection Control and Hospital Epidemiology, vol. 31, no. 12, pp. 1264-1272, 2010.

[19] B. Allegranzi, A. Gayet-Ageron, N. Damani et al., "Global implementation of WHO's multimodal strategy for improvement of hand hygiene: a quasi-experimental study," The Lancet Infectious Diseases, vol. 13, no. 10, pp. 843-851, 2013. 


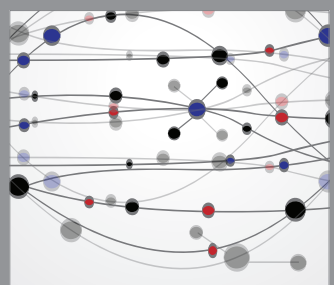

The Scientific World Journal
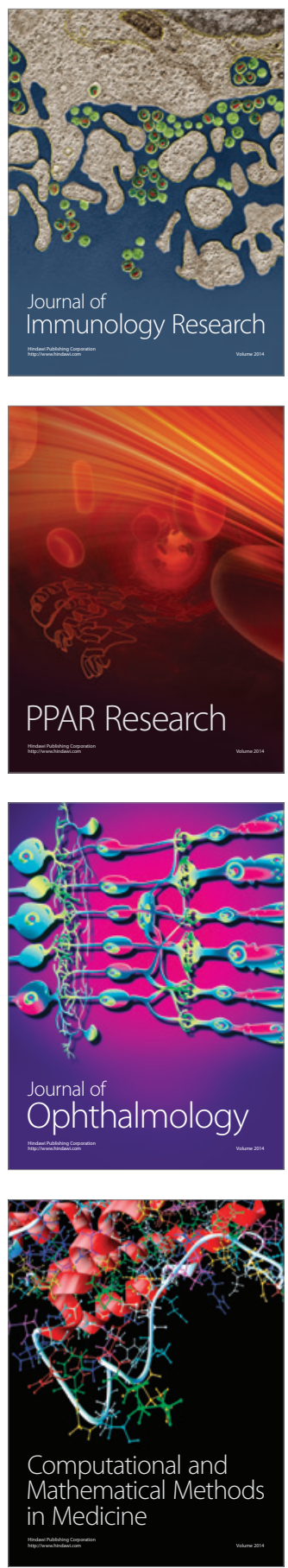

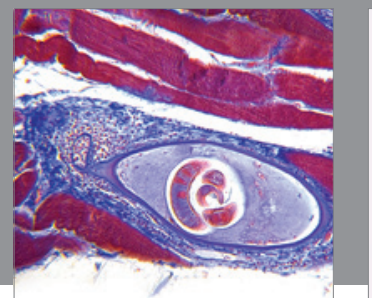

Gastroenterology

Research and Practice
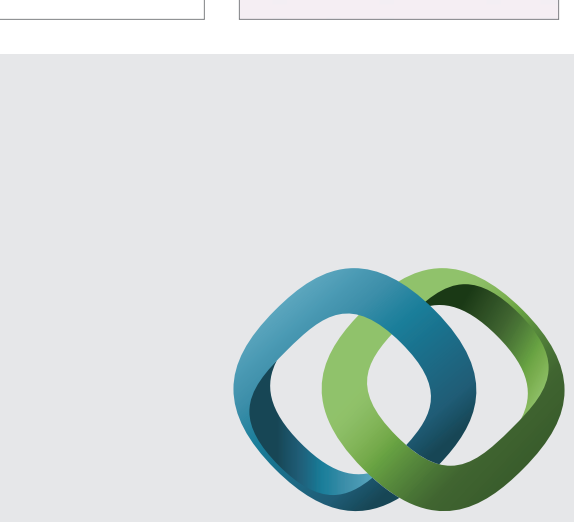

\section{Hindawi}

Submit your manuscripts at

http://www.hindawi.com
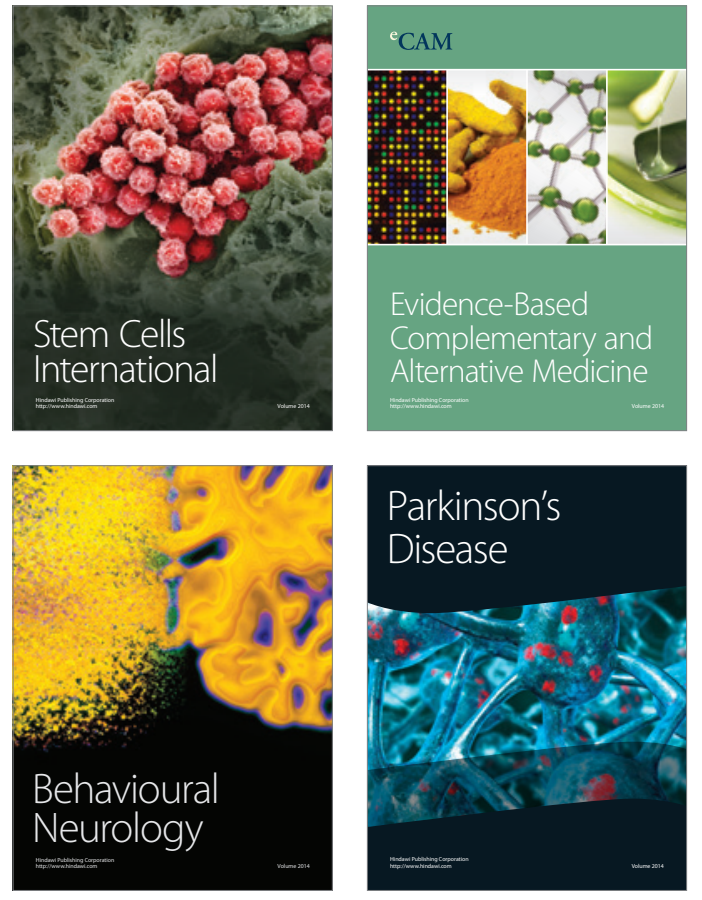
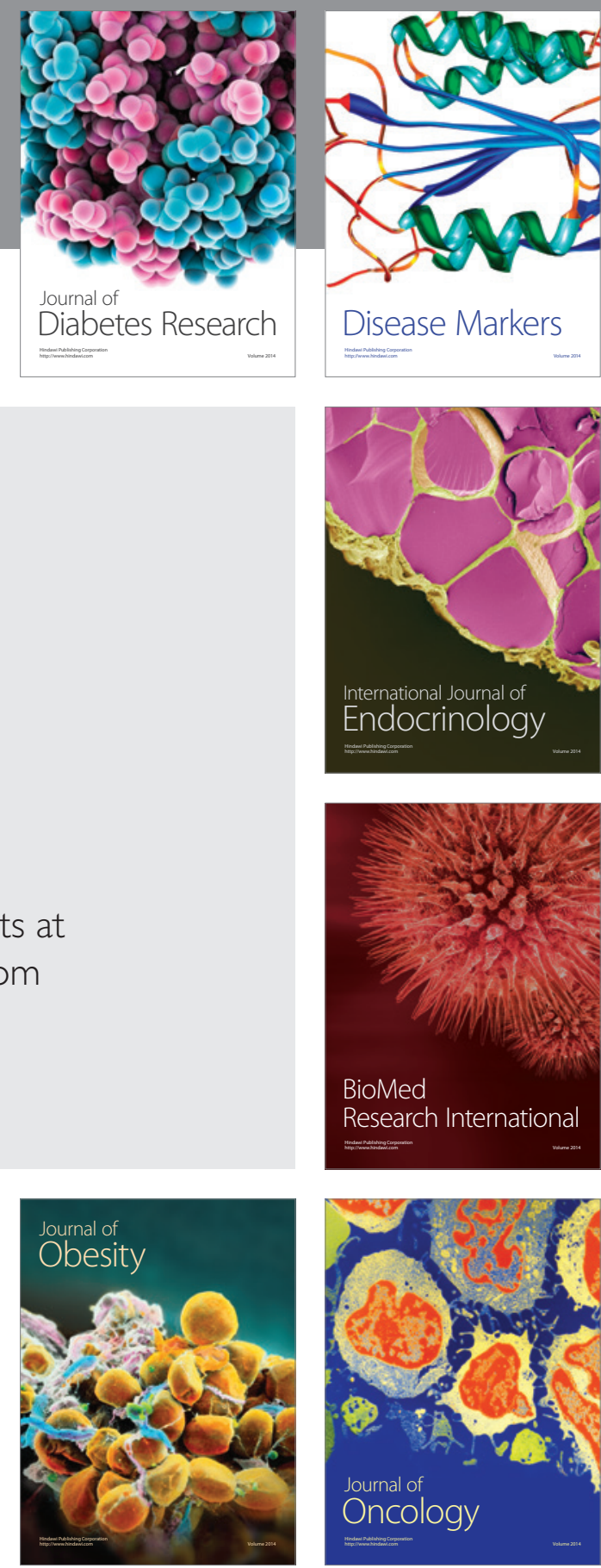

Disease Markers
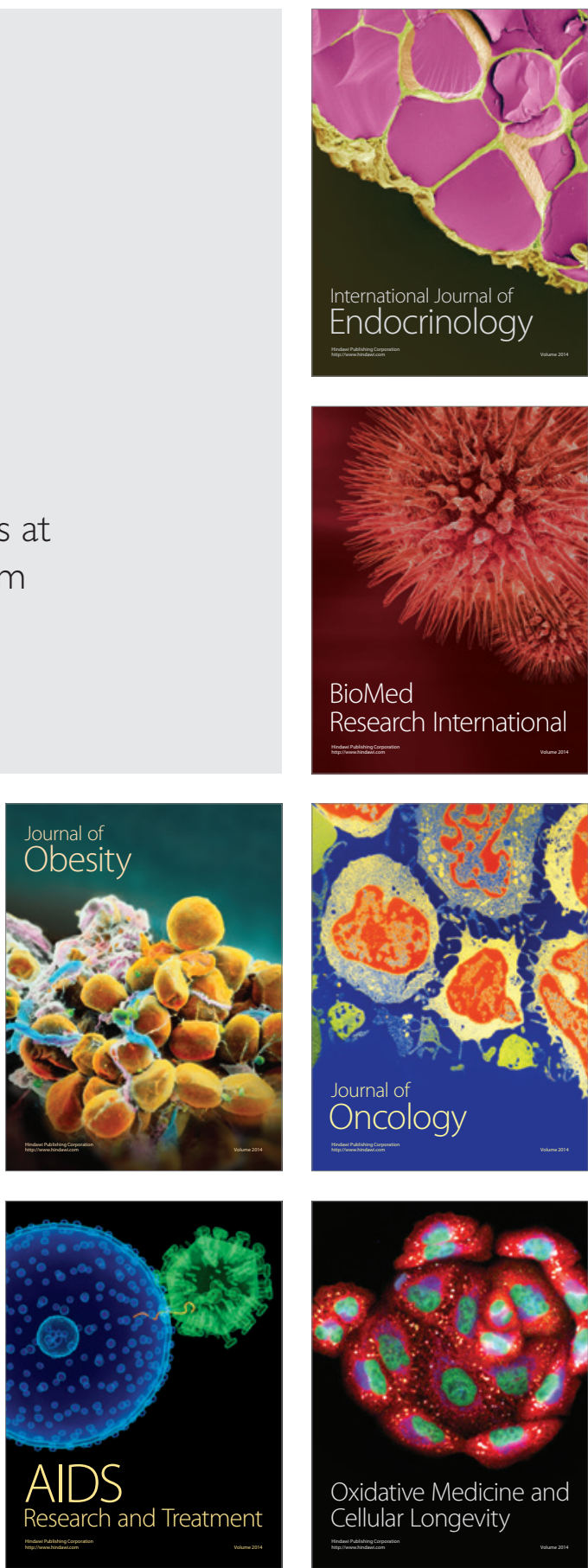